\title{
Size distribution and source of black carbon aerosol in urban Beijing during winter haze episodes
}

\section{Yunfei Wu et al.}

Correspondence to: Yunfei Wu (wuyf@mail.iap.ac.cn) and Renjian Zhang (zrj@mail.iap.ac.cn)

The copyright of individual parts of the supplement might differ from the CC BY 3.0 License. 


\section{Contents}

Fig. S1: Histogram of the lag times between the incandescence and scattering peak locations at three typical pollution levels: clean (green), polluted (blue) and heavily polluted (red).

Fig. S2: Size distributions of rBC in volume-equivalent diameter during the campaign from 24 February to 15 March 2014 (down panel) and from 9 to 27 January 2013 (up panel). The red and blue lines are the lognormal fittings to the primary and secondary modes, respectively, and the black ones correspond to the combined mode.

Fig. S3: Correlations between cations and anions: (a) $\mathrm{NH}_{4}{ }^{+}$versus $\mathrm{SO}_{4}{ }^{2-}+\mathrm{NO}_{3}{ }^{-}$; (b) Cations versus Anions

Fig. S4: Frequency histogram of the 5-min average volume-equivalent diameters (VED) of rBC without or with thin coating (black line). Gauss fitting is performed to the histogram (red line). Boxplot of the $V E D$ of non/thinly coated $\mathrm{rBC}$ is also overlapped (blue box).

Fig. S5: Geographical location of the observation site (star) and clusters of 48-h backward trajectories that arrived at the observation site $100 \mathrm{~m}$ above ground level during a campaign conducted from 24 February to 15 March 2014. Mean values of the mass concentration and volume-equivalent diameter $(V E D)$ of $\mathrm{rBC}$ (i.e., $M C_{\mathrm{rBC}}$ and $V E D_{\mathrm{rBC}}$ ), as well as the $V E D$ and number fraction of thickly coated $\mathrm{rBC}$ (i.e., $V E D_{\text {coated }}$ and $N F_{\text {coated }}$ ) for each cluster are presented. 


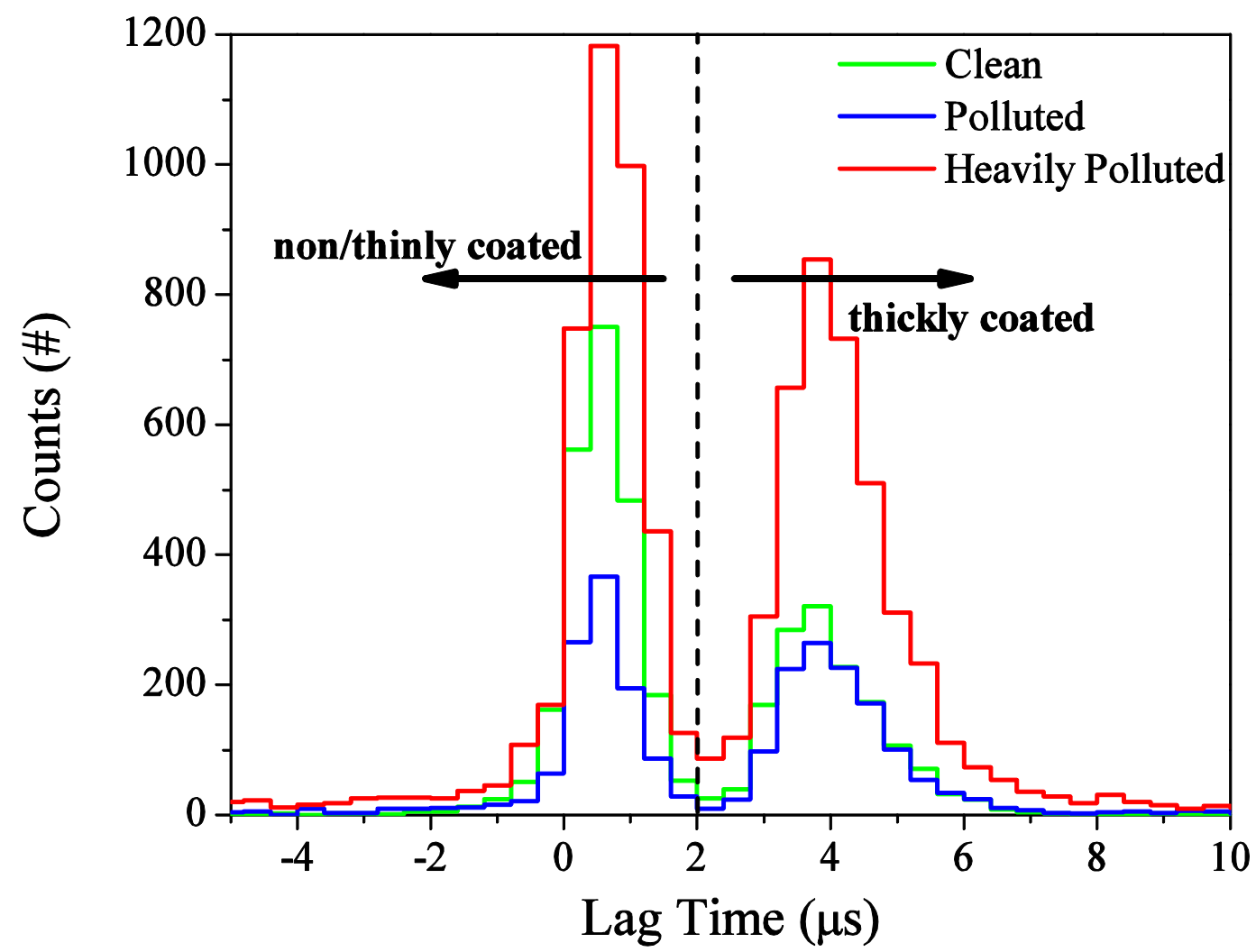

Fig. S1. Histogram of the lag times between the incandescence and scattering peak locations at three typical pollution levels: clean (green), polluted (blue) and heavily polluted (red). A bimodal distribution is found with the minimum at $\sim 2 \mu$ s regardless of the pollution level. The rBC-containing particles with the lag time greater than $2 \mu$ s were considered to be thickly coated. Otherwise, the rBC-containing particles were non/thinly coated. 

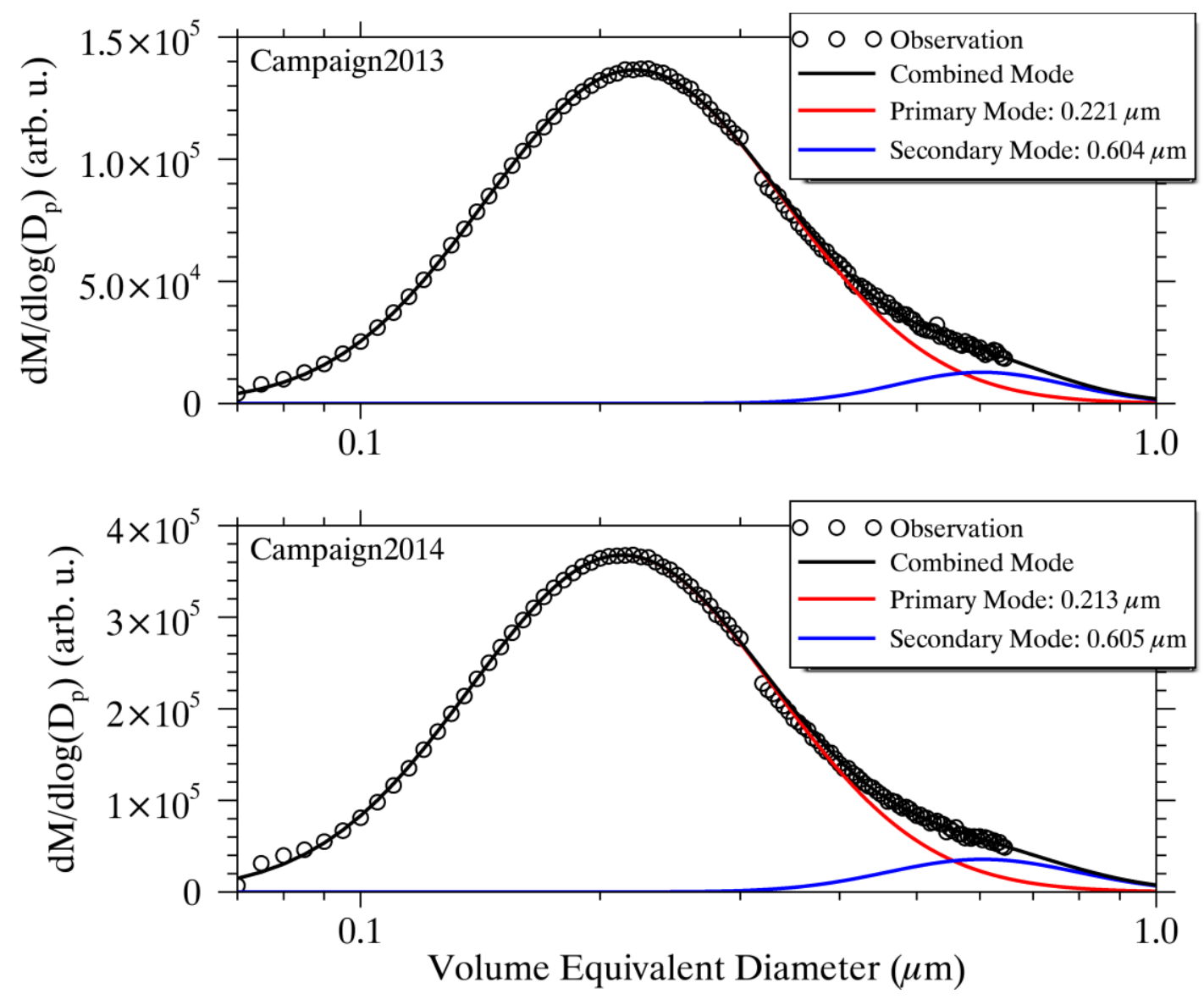

Fig. S2. Size distributions of $\mathrm{rBC}$ in volume-equivalent diameter during the campaign from 24 February to 15 March 2014 (down panel) and from 9 to 27 January 2013 (up panel). The red and blue lines are the lognormal fittings to the primary and secondary modes, respectively, and the black ones correspond to the combined mode. 

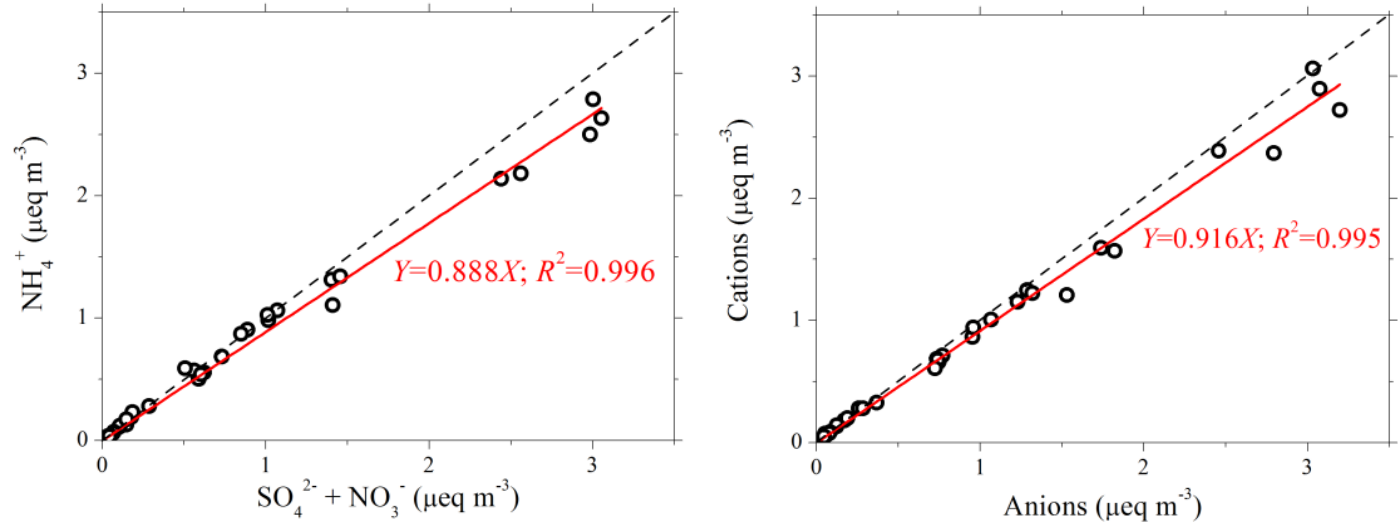

Fig. S3. Correlations between cations and anions: (a) $\mathrm{NH}_{4}{ }^{+}$versus $\mathrm{SO}_{4}{ }^{2-}+\mathrm{NO}_{3}{ }^{-}$; (b) Cations versus Anions 


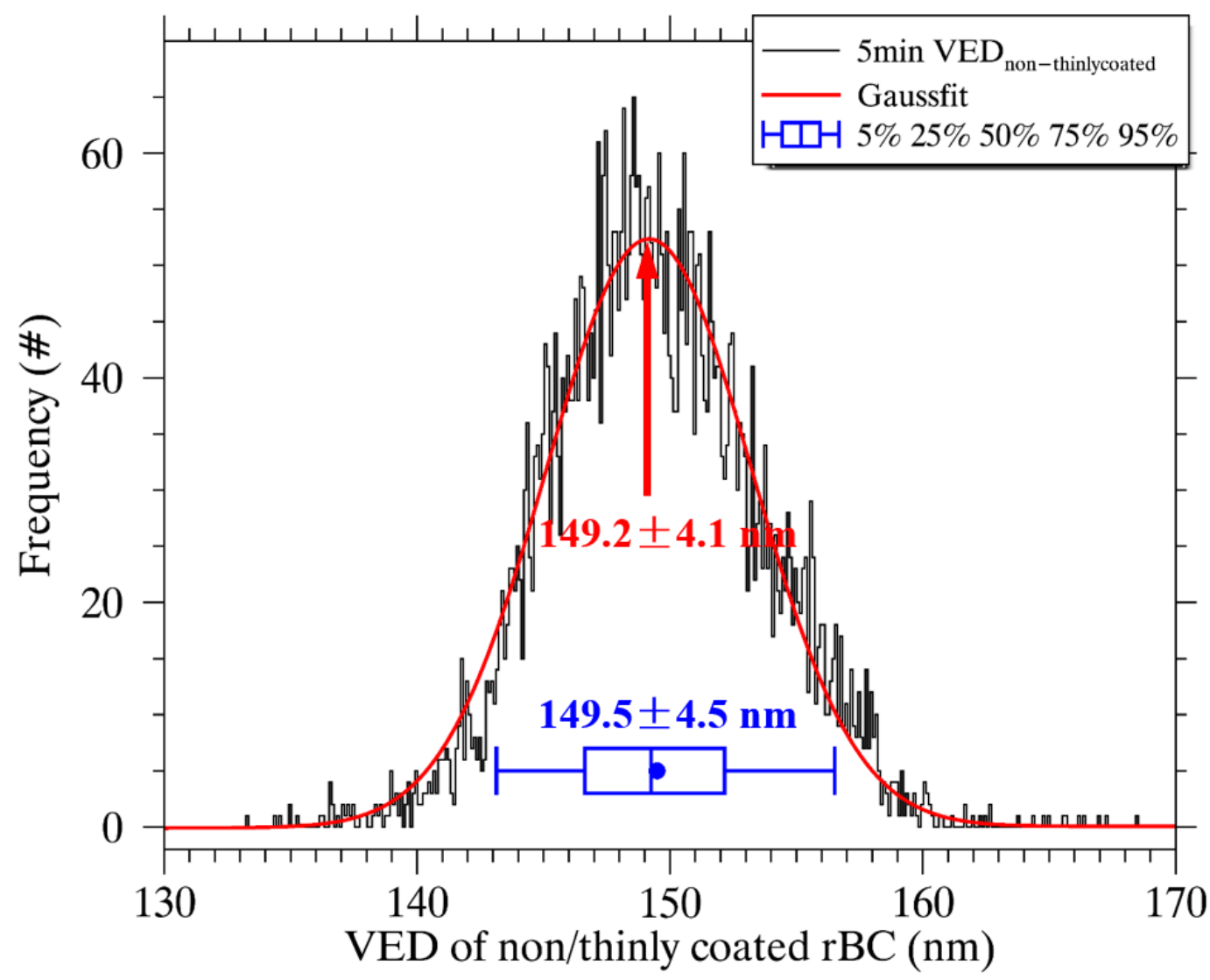

Fig. S4. Frequency histogram of the 5-min average volume-equivalent diameters (VED) of rBC without or with thin coating (black line). Gauss fitting is performed to the histogram (red line). Boxplot of the $V E D$ of non/thinly coated $\mathrm{rBC}$ is also overlapped (blue box). The peak diameter of the gauss fitting curve with a value of $149.2 \mathrm{~nm}$ is almost the same as the mean diameter with a value of $149.5 \mathrm{~nm}$. 


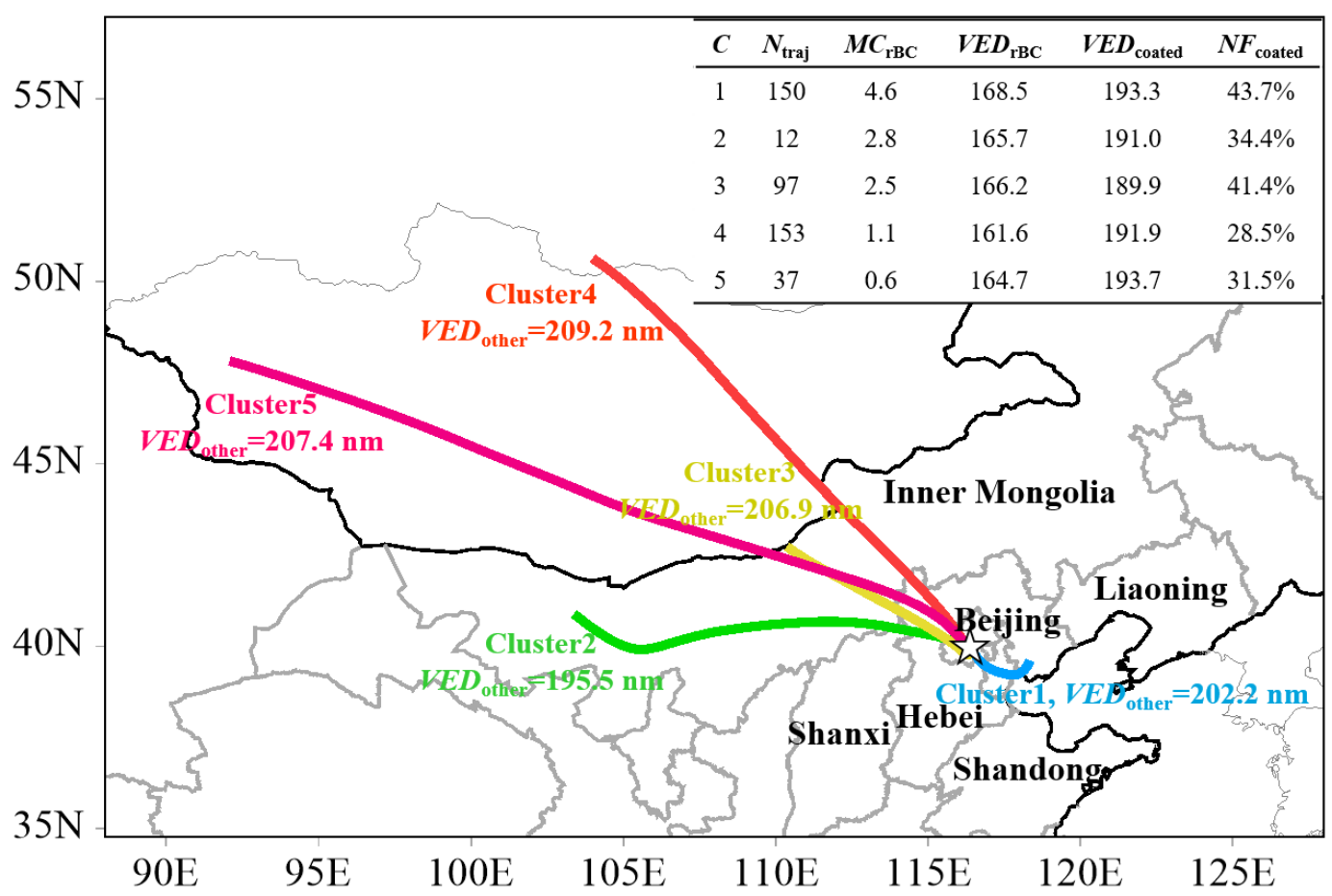

Fig. S5. Geographical location of the observation site (star) and clusters of 48-h backward trajectories that arrived at the observation site $100 \mathrm{~m}$ above ground level during a campaign conducted from 24 February to 15 March 2014. Mean values of the mass concentration and volume-equivalent diameter $(V E D)$ of $\mathrm{rBC}$ (i.e., $M C_{\mathrm{rBC}}$ and $V E D_{\mathrm{rBC}}$ ), as well as the $V E D$ and number fraction of thickly coated rBC (i.e., $V E D_{\text {coated }}$ and $N F_{\text {coated }}$ ) for each cluster are presented. 